\title{
Correction to: Peristaltic Transport of a Casson Fluid in a Non-uniform Inclined Tube with Rosseland Approximation and Wall Properties
}

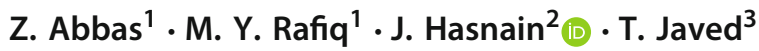

Published online: 24 November 2020

(c) King Fahd University of Petroleum \& Minerals 2020

\section{Correction to: \\ Arabian Journal for Science and Engineering https://doi.org/10.1007/s13369-020-04969-7}

In the original publication, the grant number was wrongly published as NRPU-20-4950. It should read as NRPU-6295. The original article has been corrected.

The original article can be found online at https://doi.org/10.1007/ s13369-020-04969-7.

\section{J. Hasnain}

jafar_hasnain14@yahoo.com

1 Department of Mathematics, The Islamia University of Bahawalpur, Bahawalpur 63100, Pakistan

2 Department of Computer Sciences, Bahria University Islamabad Campus, Islamabad 44000, Pakistan

3 Department of Mathematics and Statistics, International Islamic University, Islamabad 44000, Pakistan 